\title{
Prediction of Nodal Metastasis in Head and Neck Cancer Using a 3T MRI ADC Map
}

\author{
M.-C. Lee, H.-Y. Tsai, K.-S. Chuang, C.-K. Liu, and M.-K. Chen
}

\begin{abstract}
BACKGROUND AND PURPOSE: The detection of cervical nodal metastases is important for the prognosis and treatment of head and neck tumors. The purpose of this study was to assess the ability of ADC values at $3 T$ to distinguish malignant from benign lymph nodes.

MATERIALS AND METHODS: From July 2009 to June 2010, twenty-two patients (21 men and 1 woman; mean age, $49.8 \pm 9.5$ years; age range, 28-66 years) scheduled for surgical treatment of biopsy-proved head and neck cancer were prospectively and consecutively enrolled in this study. All patients were scanned on a 3T imaging unit (Verio) by using a 12-channel head coil combined with a 4-channel neck coil. Histologic findings were the reference standard for the diagnosis of lymph node metastasis.

RESULTS: The ADC values derived from the signal intensity averaged across images obtained with b-values of 0 and $800 \mathrm{~s} / \mathrm{mm}^{2}$ were $1.086 \pm 0.222 \times 10^{-3} \mathrm{~mm}^{2} / \mathrm{s}$ for benign lymph nodes and $0.705 \pm 0.118 \times 10^{-3} \mathrm{~mm}^{2} / \mathrm{s}$ for malignant lymph nodes $(P<.0001)$. When an $A D C$ value of $0.851 \times 10^{-3} \mathrm{~mm}^{2} / \mathrm{s}$ was used as a threshold value for differentiating benign from malignant lymph nodes, the best results were obtained with an accuracy of $91.0 \%$, sensitivity of $91.3 \%$, and specificity of $91.1 \%$.
\end{abstract}

CONCLUSIONS: The ADC value is a sensitive and specific parameter that can help to differentiate malignant from benign lymph nodes.

ABBREVIATIONS: AUC $=$ area under the ROC curve; $\mathrm{ROC}=$ receiver operating characteristic analysis

$\mathbf{N}$ odal metastases are an adverse prognostic factor in patients with head and neck cancer, and accurate detection can help optimize treatment. ${ }^{1}$ Anatomic imaging with CT and MR imaging is well-established in the initial diagnostic evaluation of head and neck malignancy and is widely used for treatment planning and monitoring and for posttreatment follow-up. ${ }^{2}$ On anatomic CT and MR images, certain parameters (shape, size, internal architecture, extracapsular extension, and vascular features) are associated with lymph node metastasis, but accuracy is limited, particularly in normal-sized non-necrotic lymph nodes. ${ }^{3}$

Cancer metastasis to the regional lymph nodes may be associated with alteration in water diffusivity and microcirculation of

Received August 26, 2011; accepted after revision June 23, 2012.

From the Biomedical Engineering and Environmental Sciences Department (M.-C.L., K.-S.C.), National Tsing Hua University, Hsinchu, Taiwan; Department of Medical Imaging (M.-C.L., C.-K.L.) and Superintendent's Office (M.-K.C.), Changhua Christian Hospital, Changhua, Taiwan; and Department of Medical Imaging and Radiological Sciences (H.-Y.T.), Chang Gung University, Taoyuan, Taiwan.

Ming-Che Lee and Hui-Yu Tsai contributed equally to this work.

Please address correspondence to Mu-Kuan Chen, MD, MSc, PhD, Changhua Christian Hospital, Changhua, Taiwan, 135 Nanxiao St, Changhua City, Changhua County 50006, Taiwan; e-mail: 53780@cch.org.tw

三 Indicates article with supplemental on-line table.

http://dx.doi.org/10.3174/ajnr.A3281 the nodes. ${ }^{4}$ DWI, based on intravoxel incoherent motion imaging that allows visualization of molecular diffusion and microcirculation of the blood in the capillary network of biologic tissues is an MR imaging technique that shows the potential for more specific characterization of lesions. The use of DWI to distinguish malignant from benign cervical nodes has been reported in several studies. ${ }^{4-8}$ All of these studies used 1.5T MR imaging to investigate head and neck nodal lesions and extract ADC values from DWI. After the introduction of 3T MR imaging, ADC values obtained with 3T MR imaging were used to differentiate malignant and benign head and neck cancers, ${ }^{9}$ but not to investigate head and neck lymph nodes. The purpose of this study was to assess whether ADC values from 3T MR imaging could distinguish malignant from benign cervical lymph nodes.

\section{MATERIALS AND METHODS Patients}

This study was approved by the local institutional review committee. All patients gave their informed consent before MR imaging examinations. From July 2009 to June 2010, thirtytwo patients who were scheduled for surgical treatment of biopsy-proved head and neck cancer were prospectively enrolled in this study. MR imaging was then performed on these patients before they underwent surgical neck dissection. Ten pa- 
Table 1: Tumor location, clinical tumor stages, and nodal stages according to TSE MR imaging, histopathology, and DWI

\begin{tabular}{|c|c|c|c|c|c|}
\hline \multirow{2}{*}{$\begin{array}{l}\text { Patient } \\
\text { No. }\end{array}$} & \multirow{2}{*}{$\begin{array}{l}\text { Primary Tumor } \\
\text { Location }\end{array}$} & \multirow{2}{*}{$\begin{array}{c}\text { Clinical } \\
\text { Tumor } \\
\text { Stage }\end{array}$} & \multicolumn{3}{|c|}{ Nodal Stage } \\
\hline & & & TSE & Histopathology & DWI \\
\hline 1 & Buccal & $\mathrm{Tl}$ & No & No & NO \\
\hline 2 & Oropharynx (palate) & $\mathrm{T} 2$ & N2b & N2b & No \\
\hline 3 & Buccal & T3 & $\mathrm{N} 2 \mathrm{~b}$ & $\mathrm{~N} 1$ & N1 \\
\hline 4 & Tongue & $\mathrm{Tl}$ & $\mathrm{Nx}$ & No & No \\
\hline 5 & Mouth floor & $\mathrm{Tl}$ & NO & No & No \\
\hline 6 & Tongue & $\mathrm{T} 2$ & No & No & No \\
\hline 7 & Tongue & T4a & $\mathrm{N} 2 \mathrm{~b}$ & $\mathrm{~N} 2 \mathrm{c}$ & $\mathrm{N} 2 \mathrm{c}$ \\
\hline 8 & Tongue & $\mathrm{Tl}$ & N1 & No & N1 \\
\hline 9 & Tongue & $\mathrm{T} 2$ & No & No & No \\
\hline 10 & $\begin{array}{l}\text { Hypopharynx and } \\
\text { epiglottis }\end{array}$ & $\mathrm{T} 2$ & N1 & No & $\mathrm{N} 1$ \\
\hline 11 & Tongue & $\mathrm{Tl}$ & NO & No & No \\
\hline 12 & Palate & T4a & $\mathrm{N} 2 \mathrm{~b}$ & No & No \\
\hline 13 & Tongue & $\mathrm{T1}$ & NO & No & No \\
\hline 14 & Tongue & T4a & $\mathrm{N} 2 \mathrm{~b}$ & No & No \\
\hline 15 & Tongue & $\mathrm{T} 2$ & No & No & No \\
\hline 16 & Tongue & T3 & $\mathrm{N} 2 \mathrm{c}$ & No & $\mathrm{N} 2 \mathrm{c}$ \\
\hline 17 & Tongue & $\mathrm{T} 2$ & No & No & No \\
\hline 18 & Tongue & T4a & $\mathrm{N} 2 \mathrm{~b}$ & $\mathrm{~N} 2 \mathrm{~b}$ & $\mathrm{~N} 2 \mathrm{~b}$ \\
\hline 19 & Tongue & $\mathrm{T} 2$ & NO & $\mathrm{N} 2 \mathrm{~b}$ & $\mathrm{~N} 2 \mathrm{~b}$ \\
\hline 20 & $\begin{array}{l}\text { Hypopharynx and } \\
\text { pyriform sinus }\end{array}$ & T4a & N1 & $\mathrm{N} 2 \mathrm{~b}$ & N1 \\
\hline 21 & Retromolar & $\mathrm{T} 4 \mathrm{~b}$ & $\mathrm{~N} 2 \mathrm{~b}$ & $\mathrm{~N} 2 \mathrm{~b}$ & $\mathrm{~N} 2 \mathrm{~b}$ \\
\hline 22 & $\begin{array}{l}\text { Hypopharynx and } \\
\text { pyriform sinus }\end{array}$ & $\mathrm{T} 2$ & $\mathrm{~N} 2 \mathrm{c}$ & $\mathrm{N} 2 \mathrm{c}$ & $\mathrm{N} 2 \mathrm{c}$ \\
\hline
\end{tabular}

tients were excluded from the study cohort: 1) four patients whose images had motion artifacts, 2) three patients whose treatment changed to nonsurgical treatment, and 3) three patients who had surgical excision of neck nodes before MR imaging because of changes in disease status.

The remaining 22 patients ( 21 men and 1 woman; mean age, $49.8 \pm 9.5$ years; age range, $28-66$ years) underwent combined conventional TSE MR imaging and DWI before undergoing surgery to remove tumors and lymph nodes. The final diagnosis was based on pathologic findings in surgical resection specimens.

The tumor stage was determined according to the size of the tumor, the muscle invasion, and the involvement of adjacent structures as per the American Joint Committee on Cancer staging system. ${ }^{10}$

\section{MR Imaging Technique}

All MR imaging studies were performed by using a 3T imaging unit (Verio; Siemens, Erlangen, Germany) with a 12-channel head coil combined with a 4-channel neck coil. During MR imaging sequences, patients were instructed to hold still and not to swallow to avoid motion artifacts.

The following protocols were used in all patients. Before contrast administration, the patients underwent 3 scanning sequences: 1) transverse T2-weighted TSE MR imaging (TR/TE, 3500/88 ms; section thickness, $3 \mathrm{~mm}$; FOV, $230 \mathrm{~mm}$; intersection gap, 0.9 mm; image matrix, $314 \times 448$; number of signals acquired, 1); 2) transverse T1-weighted TSE MR imaging (TR/TE, 700/10 ms; section thickness, $3 \mathrm{~mm}$; FOV, $230 \mathrm{~mm}$; intersection gap, $0.9 \mathrm{~mm}$; image matrix, $314 \times 448$; number of signals acquired, 1); 3) DWI of the head and neck in the transverse plane by using a spin-echo single-shot echo-planar imaging sequence (TR/TE, 8000/77 ms;
Table 2: 3T ADC values in malignant neck lymph nodes

\begin{tabular}{|c|c|c|c|c|c|c|}
\hline $\begin{array}{l}\text { Patient } \\
\text { No. }\end{array}$ & $\begin{array}{l}\text { Age } \\
\text { (yr) }\end{array}$ & Sex & Lesion & $\begin{array}{l}\text { Lymph } \\
\text { Node }^{a}\end{array}$ & $\begin{array}{l}\text { LN Size } \\
(\mathrm{cm})\end{array}$ & $\begin{array}{c}\text { ADC } \\
\left(\times 10^{-3} \mathrm{~mm}^{2} / \mathrm{s}\right)^{a}\end{array}$ \\
\hline \multirow[t]{5}{*}{18} & 44 & $M$ & Tongue cancer & LN3 & 0.84 & $0.715 \pm 0.126$ \\
\hline & & & & LN6 & 1.08 & $0.635 \pm 0.143$ \\
\hline & & & & LN13 & 0.63 & $0.460 \pm 0.165$ \\
\hline & & & & LN14 & 0.78 & $0.735 \pm 0.067$ \\
\hline & & & & LN16 & 0.60 & $0.678 \pm 0.193$ \\
\hline 20 & 59 & M & $\begin{array}{l}\text { Hypopharynx } \\
\text { cancer }\end{array}$ & LN1 & 0.56 & $0.811 \pm 0.069$ \\
\hline \multirow[t]{5}{*}{7} & 44 & M & Tongue cancer & LN4 & 1.44 & $0.753 \pm 0.089$ \\
\hline & & & & LN5 & 0.89 & $0.884 \pm 0.207$ \\
\hline & & & & LN13 & 0.36 & $0.723 \pm 0.162$ \\
\hline & & & & LN15 & 0.74 & $0.437 \pm 0.221$ \\
\hline & & & & LN19 & 0.44 & $0.666 \pm 0.270$ \\
\hline \multirow[t]{6}{*}{22} & 60 & M & $\begin{array}{l}\text { Hypopharynx } \\
\text { cancer }\end{array}$ & LN1 & 1.04 & $0.655 \pm 0.090$ \\
\hline & & & & LN2 & 1.36 & $0.731 \pm 0.082$ \\
\hline & & & & LN3 & 1.35 & $0.751 \pm 0.127$ \\
\hline & & & & LN4 & 1.58 & $0.659 \pm 0.073$ \\
\hline & & & & LN5 & 1.82 & $0.712 \pm 0.154$ \\
\hline & & & & LN6 & 1.72 & $0.598 \pm 0.028$ \\
\hline \multirow[t]{2}{*}{21} & 50 & M & Oral cancer & LN2 & 0.85 & $0.676 \pm 0.139$ \\
\hline & & & & LN7 & 0.50 & $0.816 \pm 0.094$ \\
\hline 3 & 51 & M & Buccal cancer & LN14 & 0.99 & $0.559 \pm 0.043$ \\
\hline \multirow[t]{3}{*}{19} & 28 & $\mathrm{~F}$ & Tongue cancer & LN2 & 0.55 & $0.839 \pm 0.057$ \\
\hline & & & & LN6 & 0.67 & $0.875 \pm 0.090$ \\
\hline & & & & LN7 & 1.84 & $0.851 \pm 0.109$ \\
\hline
\end{tabular}

Note:- LN indicates lymph node.

${ }^{\mathrm{a}}$ Mean $\pm \mathrm{SD}$.

section thickness, $3 \mathrm{~mm}$; intersection gap, $0.9 \mathrm{~mm}$; FOV, $230 \mathrm{~mm}$; image matrix, $122 \times 144$; number of signals acquired, 3 ). DWI images were obtained at $b$ factors of 0 and $800 \mathrm{~s} / \mathrm{mm}^{2}$ for eachsection in the same sequence. ${ }^{8}$ The scan range was from the skull base to the suprasternal notch. The ADC maps were then automatically reconstructed on the scanner console.

After a bolus injection of $0.1 \mathrm{mmol} / \mathrm{kg}$ of gadodiamide (Omniscan; GE Healthcare, Cork, Ireland), the patients underwent 1 scanning sequence: transverse fat-suppressed T1-weighted TSE MR imaging (TR/TE, 700/10 ms; section thickness, 3 mm; FOV, $230 \mathrm{~mm}$; intersection gap, $0.9 \mathrm{~mm}$; image matrix, $314 \times 448$; number of signals acquired, 1 ).

\section{Image Analysis}

One radiologist (C.-K.L.) with 6 years of experience in MR imaging of the head and neck region interpreted MR images on the basis of T2- and T1-weighted images. A lymph node was considered to be metastatic on the basis of the nodal size, contour irregularity, or heterogeneous contrast enhancement. ${ }^{5}$ The sizes of all lymph nodes were measured by the radiologist (C.-K.L.) in their minimal transverse diameter. The nodal size criteria larger than 2 mm were used. ${ }^{11}$

The DWI ADC maps were automatically reconstructed by standard software on the scanner console. The region-of-interest position was based on the T2- and T1-weighted contrast-enhanced MR images and was directly drawn on the ADC map for each node by a radiologist (C.-K.L.). Region-of-interest measurements in the lymph nodes included the largest solid component and excluded obviously necrotic or cystic regions. ${ }^{7,12}$ The ADC value was then obtained from the ADC maps. All lymph nodes 


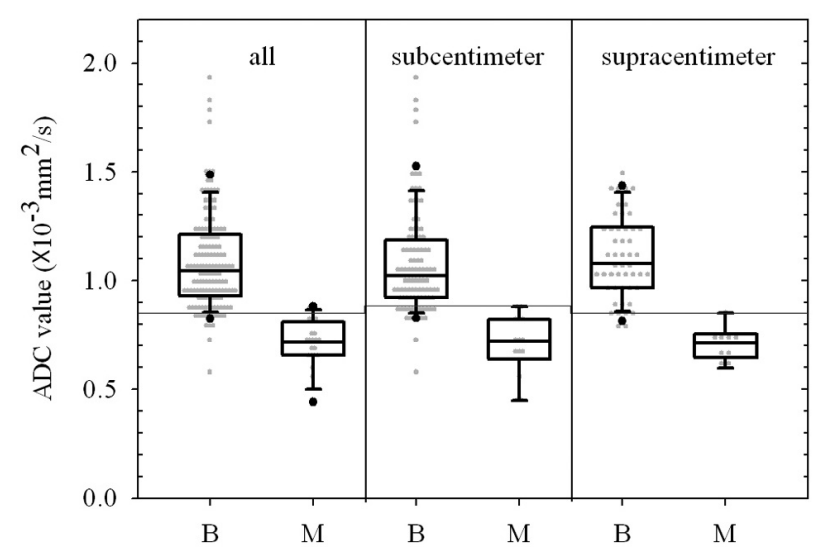

FIG 1. Box-and-whisker plot presenting the scatterplot of mean apparent diffusion coefficients in all lymph nodes and subcentimeter and supracentimeter lymph nodes.

seen on DWI images were proceeded ADC calculation except lymph node diameters less than region-of-interest extent.

The nodal stage was determined according to the size, number, and location of the lymph nodes by preoperative MR images.

\section{Pathologic Evaluation}

Histologic findings from surgical resection were the reference standard for primary tumor metastasis to the lymph nodes. Surgeons carefully reviewed MR images on the PACS, and intraoperatively, the specimens were matched with the lymph nodes as imaged on T2- and T1-weighted contrast-enhanced MR images. To ensure that the node removed surgically during neck dissection was the same node seen at MR imaging, the lymph nodes were excised adjacent to reference structures to determine the relationship between the excised nodes and the surrounding structures. After surgery, each node was carefully delineated and tagged for pathologic diagnosis. The histopathologic and radiologic findings were correlated on an individual nodal basis.

After the histopathologic and radiologic findings for each lymph node were correlated, the optimal $\mathrm{ADC}_{b=0-800}$ threshold for differentiating malignant from benign lymph nodes was determined by using ROC analysis. ${ }^{5}$ The sensitivity and specificity of the DWI method were then calculated.

For pathologic metastatic lymph nodes, the ratio of intranodal tumor deposits was measured by an experienced pathologist according to the lymph node size (short-axis diameter) and the size of intranodal tumor deposits (maximum diameter of metastatic foci in each lymph node).

\section{Statistical Analysis}

Statistical analyses were performed by using statistical software MedCalc for Windows (Version 9.4; MedCalc Software, Mariakerke, Belgium). Numeric data are reported as means \pm SD. A box-and-whisker plot was used to depict the scatterplot of mean ADC values in benign and malignant lymph nodes. The ROC curve was performed to evaluate the diagnostic capability of the $\mathrm{ADC}$ value and to determine the cutoff values for differentiating malignant from benign lymph nodes.

The AUC was used to measure the performance of using the ADC values as effective indicators for discrimination. An independent-sample $t$ test was used to compare the mean diameters of the benign and malignant lymph nodes.

\section{RESULTS}

A total of 169 cervical lymph nodes were detected in 22 untreated patients ( 21 men and 1 woman; mean age, $49.8 \pm 9.5$ years; age range, 28-66 years). There were 17 patients with unilateral neck dissection and 5 patients with bilateral neck dissection. The specimens were divided into level I to level V, and then resected lymph nodes were carefully matched with MR images and pathologic evaluation. The location and clinical tumor stage were based on physical examinations and preoperative MR images. The nodal stage was determined by the conventional TSE MR images, DWI images, and histopathology for each patient. The tumor stages and nodal stages are shown in Table 1 . Of 169 cervical lymph nodes, 146 were benign and 23 were malignant. The sizes of 23 malignant lymph nodes ranged from 0.36 to $1.84 \mathrm{~cm}$ (in minimal transverse diameter), and ADC values ranged from 0.437 to 0.884 $10^{-3} \mathrm{~mm}^{2} / \mathrm{s}$ (Table 2). The box-and-whisker plot (Fig 1) presents the distribution of mean ADC values in benign and malignant lymph nodes. All lymph nodes were placed in 1 of 2 groups according to their diameters: supracentimeter $(n=58)$ or subcentimeter $(n=111)$ lymph nodes. The mean ADC values for the benign and malignant lesions were $1.086 \pm 0.222$ and $0.705 \pm$ $0.118 \times 10^{-3} \mathrm{~mm}^{2} / \mathrm{s}$ for all lymph nodes, $1.076 \pm 0.238$ and $0.705 \pm 0.141 \times 10^{-3} \mathrm{~mm}^{2} / \mathrm{s}$ for subcentimeter lymph nodes, and $1.105 \pm 0.188$ and $0.705 \pm 0.077 \times 10^{-3} \mathrm{~mm}^{2} / \mathrm{s}$ for supracentimeter lymph nodes. The detailed data are summarized in Table 3.

Figure 2 shows corresponding ROC curves of ADC values used for differentiating malignant from benign lymph nodes $(P<$ .0001). Patients with hypopharynx squamous cell carcinoma who had supracentimeter and subcentimeter metastatic lymph nodes are shown in Figs 3 and 4, respectively.

One patient (Table 1, patient 19) with pathologically proved

Table 3: ADC value based on supracentimeter and subcentimeter lymph node size

\begin{tabular}{|c|c|c|c|c|c|c|c|c|c|}
\hline \multirow[b]{2}{*}{$\mathrm{LN}^{(\mathrm{a})}$ group } & \multirow{2}{*}{$\begin{array}{l}\text { LN Diameter } \\
\text { (cm) }\end{array}$} & \multirow[b]{2}{*}{$\mathrm{B} / \mathrm{M}$} & \multirow{2}{*}{$\begin{array}{c}\text { ADC Cutoff } \\
\text { Value } \\
\left(\times 10^{-3} \mathrm{~mm}^{2} / \mathrm{s}\right)\end{array}$} & \multicolumn{2}{|c|}{$\begin{array}{c}\text { ADC Value } \\
\left(\times 10^{-3} \mathrm{~mm}^{2} / \mathrm{s}\right)^{\mathrm{a}}\end{array}$} & \multirow{2}{*}{$\begin{array}{c}\text { Sensitivity } \\
(\%)\end{array}$} & \multirow{2}{*}{$\begin{array}{l}\text { Specificity } \\
(\%)\end{array}$} & \multirow[b]{2}{*}{$P$} & \multirow[b]{2}{*}{$A U C^{b}$} \\
\hline & & & & Benign & Malignant & & & & \\
\hline All & $0.27-2.89$ & $146 / 23$ & 0.851 & $\begin{array}{c}1.086 \pm 0.222 \\
(0.578-1.932)\end{array}$ & $\begin{array}{l}0.705 \pm 0.118 \\
(0.437-0.884)\end{array}$ & 91.3 & 91.1 & $<.0001$ & $\begin{array}{c}0.97 \\
(0.93-0.99)\end{array}$ \\
\hline Subcentimeter & $0.27-0.99$ & $97 / 14$ & 0.884 & $\begin{array}{l}1.076 \pm 0.238 \\
(0.578-1.932)\end{array}$ & $\begin{array}{l}0.705 \pm 0.141 \\
(0.437-0.884)\end{array}$ & 100 & 80.4 & $<.0001$ & $\begin{array}{c}0.95 \\
(0.90-0.98)\end{array}$ \\
\hline Supracentimeter & $1.00-2.89$ & $49 / 9$ & 0.851 & $\begin{array}{l}1.105 \pm 0.188 \\
(0.771-1.494)\end{array}$ & $\begin{array}{l}0.705 \pm 0.077 \\
(0.598-0.851)\end{array}$ & 100 & 91.8 & $<.0001$ & $\begin{array}{c}0.97 \\
(0.92-0.99)\end{array}$ \\
\hline
\end{tabular}

Note:- LN indicates lymph node; B/M, benign/malignant.

${ }^{a}$ Mean \pm SD. Parentheses show range of ADC values.

b Parentheses show $95 \%$ confidential intervals. 


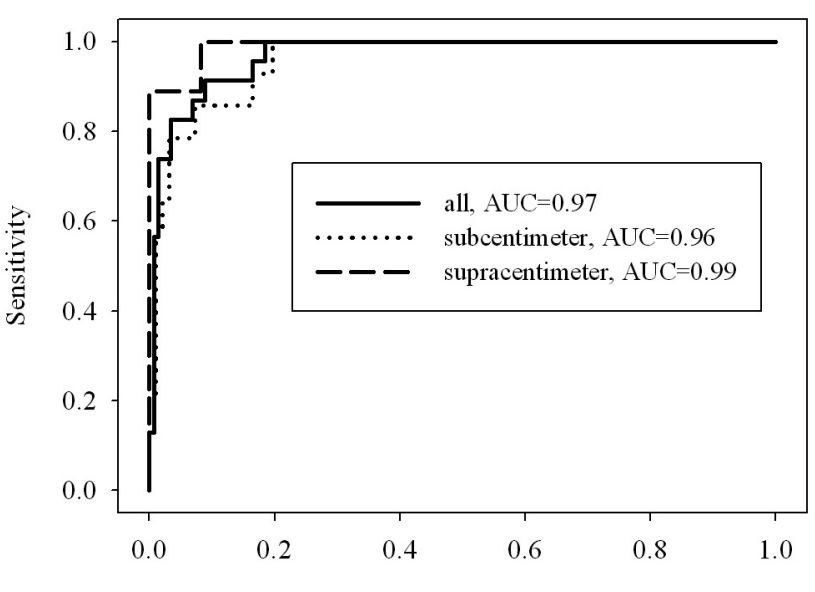

1-Specificity

FIG 2. ROC curves were created for all lymph nodes and subcentimeter and supracentimeter lymph nodes. The cutoff $A D C$ values were $0.851 \times 10^{-3} \mathrm{~mm}^{2} / \mathrm{s}, 0.884 \times 10^{-3} \mathrm{~mm}^{2} / \mathrm{s}$, and $0.851 \times 10^{-3}$ $\mathrm{mm}^{2} / \mathrm{s}$ for all lymph nodes and subcentimeter and supracentimeter lymph nodes and were used to differentiate malignant from benign lymph nodes. The best results obtained were sensitivities of $91.3 \%$, $100 \%$, and $100 \%$, specificities of $91.1 \%, 80.4 \%$, and $91.8 \%$, respectively. The areas under the curve were $0.97,0.96$, and 0.99

squamous cell carcinoma of the right tongue had a right level I lymph node metastasis. Conventional TSE MR images showed a normal regular contour, a minimal transverse diameter of 0.55 $\mathrm{cm}$, and homogeneous enhancement. The DWI ADC value was
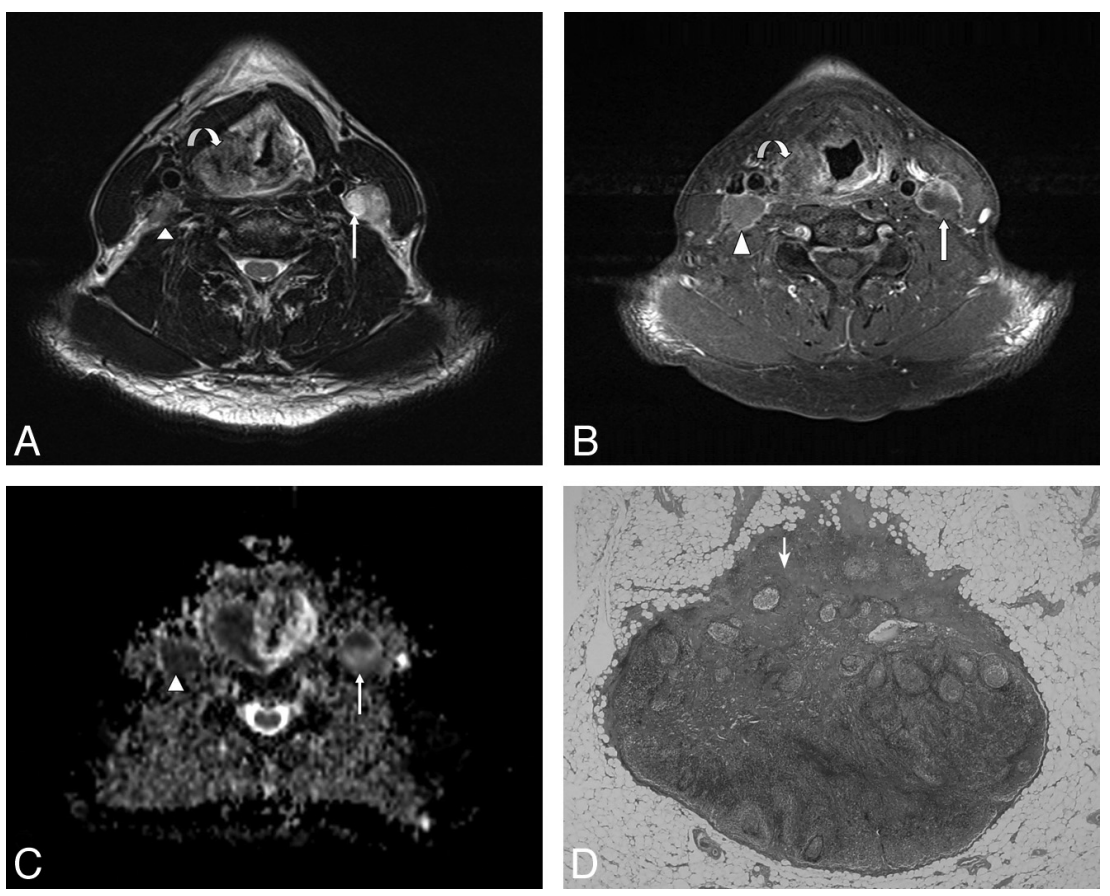

FIG 3. A 60-year-old male patient with pathologically proved squamous cell carcinoma of the hypopharynx. A, The axial T2-weighted MR image shows an infiltrative neoplasm in the right pyriform apex of the hypopharynx (curved arrow) and enlarged lymph nodes in the bilateral level III, showing heterogeneous signal intensity (arrow and arrowhead). B, The axial postgadolinium fat-suppressed T1-weighted FSE image reveals mild peripheral enhancement in the right pyriform apex tumor (curved arrow) and heterogeneous enhancement in bilateral level III lymph nodes (arrow and arrowhead). C, The ADC value within the right level III lymph node measured $0.712 \times 10^{-3} \mathrm{~mm}^{2} / \mathrm{s}$ (arrowhead), and the left level III lymph node measured $0.659 \times$ $10^{-3} \mathrm{~mm}^{2} / \mathrm{s}$ (arrow). D, Corresponding H\&E-stained histopathologic slide shows intranodal tumor cell metastasis (arrow) (original magnification, $\times 20$ ). lower than the cutoff value though, representing malignancy (Fig. 5).

The mean diameters of the benign and malignant lymph nodes of the benign lymph nodes, comparison of the groups of and malignant nodes by using an independent-samples nificance $(P=.192)$.

The conventional TSE MR imaging findings based on morphology and size were correlated with pathologic findings for each patient. The sensitivity and specificity of conventional TSE MR imaging findings to detect malignant nodal involvement were $87.5 \%$ and $57.1 \%$, respectively. The mean percentage of the tumor deposit within the affected nodes measured by a pathologist was $74.3 \% \pm 30.2 \%$.

\section{DISCUSSION}

Differentiation of benign from malignant nodes is essential for tumor staging, treatment planning, prognostication, and follow-up both during and after treatment. Diffusion imaging enables characof tissue at a microscopic level, emphasizing a mechanism at is different from $\mathrm{T} 1$ and $\mathrm{T} 2$ relaxation ${ }^{13,14}$ and potentially imoving the performance of MR imaging. ${ }^{13,15,16}$

Differences in ADC values between benign and malignant processes of the head and neck have been demonstrated in several studies. ${ }^{4-}$ 9,12,13,17-19 The On-line Table summarizes the studies that have investigated head and neck lesions with 1.5T or 3T MR imaging. These studies determined the cutoff ADC values for differentiating malignant from benign head and neck cancers or lymph nodes. For example, Srinivasan et $\mathrm{al}^{9}$ used $3 \mathrm{~T}$ MR imaging to determine an ADC cutoff value of $1.3 \times$ $10^{-3} \mathrm{~mm}^{2} / \mathrm{s}$ for differentiating malignant $\left(1.071 \pm 0.293 \times 10^{-3} \mathrm{~mm}^{2} / \mathrm{s}\right)$ from benign $\left(1.505 \pm 0.487 \times 10^{-3} \mathrm{~mm}^{2} / \mathrm{s}\right)$ head and neck tumors.

Previous studies ${ }^{4-8}$ investigated neck lymph nodes at $1.5 \mathrm{~T}$. The cutoff values were from 0.94 to $1.38 \times 10^{-3} \mathrm{~mm}^{2} / \mathrm{s}^{5-7}$ Mean ADC values for benign (1.19 to $\left.1.64 \times 10^{-3} \mathrm{~mm}^{2} / \mathrm{s}\right)$ were higher than malignant $\left(0.85\right.$ to $\left.1.09 \times 10^{-3} \mathrm{~mm}^{2} / \mathrm{s}\right)$ lymph nodes. Sumi et al, ${ }^{4}$ however, found that metastatic nodes $(0.410 \pm 0.105 \times$ $10^{-3} \mathrm{~mm}^{2} / \mathrm{s}$ ) had higher ADC values than benign nodes $\left(0.302 \pm 0.062 \times 10^{-3}\right.$ $\mathrm{mm}^{2} / \mathrm{s}$ ). These differences cannot be attributed solely to the different b-value setting for ADC calculations. The higher number of necrotic metastatic lymph nodes included in the Sumi et al study may have contributed to the discrep- 

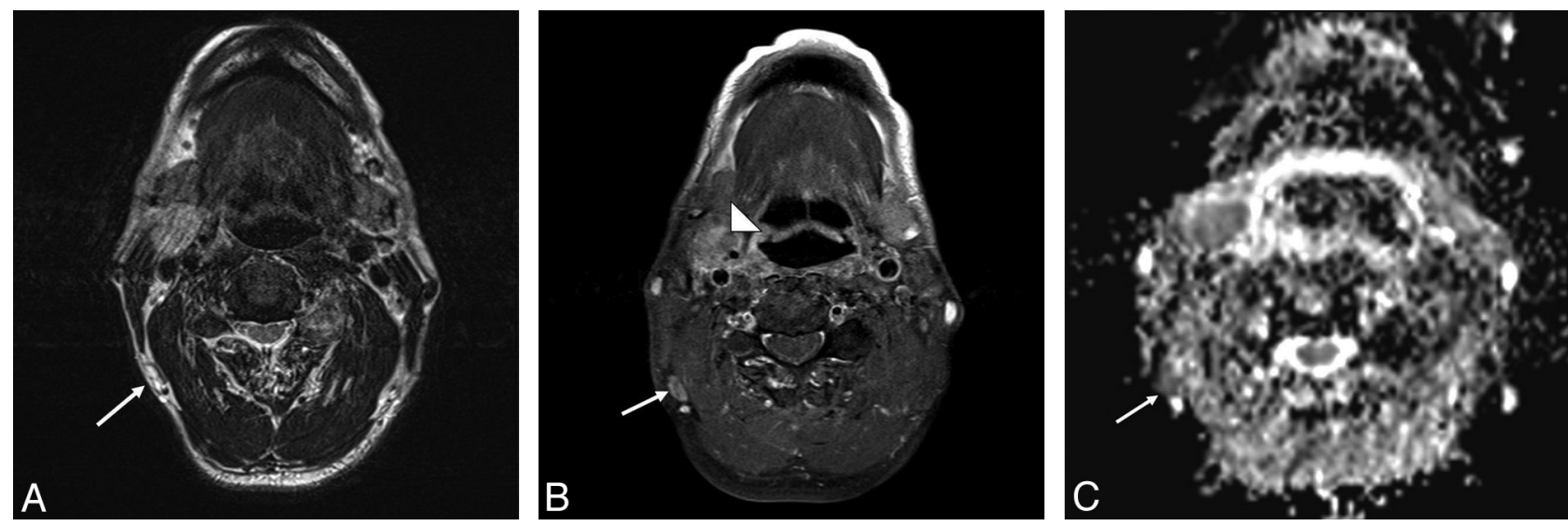

FIG 4. A 59-year-old male patient with pathologically proved squamous cell carcinoma of the hypopharynx and metastatic lymphadenopathy of the right level $\mathrm{V}$ lymph nodes. $A$, The axial T2-weighted MR image shows a subcentimeter lymph node with high signal intensity at right level $\mathrm{V}$ (arrow). B, The axial postgadolinium fat-suppressed T1-weighted image reveals moderate enhancement in the right pyriform apex tumor (arrowhead) and heterogeneous enhancement in the right level V lymph nodes (arrow). C, The ADC value was $0.811 \times 10^{-3} \mathrm{~mm}^{2} / \mathrm{s}(\mathrm{arrow})$ in the right level $\mathrm{V}$ lymph node.

ancy. ${ }^{4}$ In our study, the ADC cutoff value $\left(0.851 \times 10^{-3} \mathrm{~mm}^{2} / \mathrm{s}\right)$ is lower than the values found in other studies ${ }^{5-7}$ for the detection of malignant head and neck lymph nodes. The ADC value is cal-
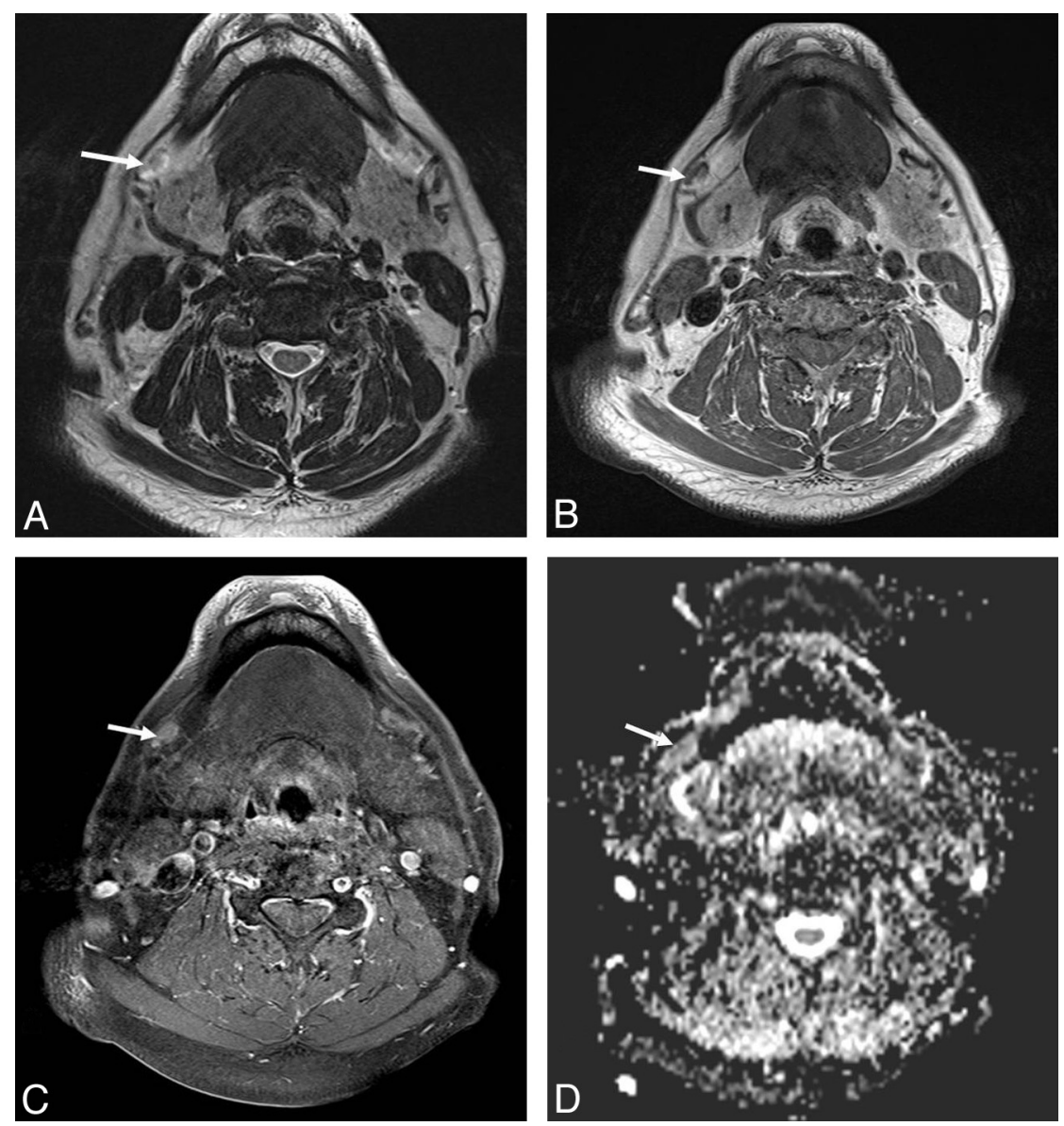

FIG 5. A 28-year-old female patient with pathologically proved squamous cell carcinoma of the right tongue body with right level I lymph node metastasis. $A$, The axial T2-weighted MR image shows no necrotic change of the right level I lymph node (arrow). $B$, The axial T1-weighted MR image shows normal configuration and size of the right level I lymph node with fatty content in its hilar region (arrow). C, The axial postgadolinium fat-suppressed T1-weighted FSE image reveals homogeneous enhancement of the right level I lymph node (arrow). $D$, The ADC value within the right level I lymph node measured $0.839 \times 10^{-3} \mathrm{~mm}^{2} / \mathrm{s}$ (arrow). culated by the equation, $\mathrm{ADC}=\ln \left(\mathrm{SI}_{1} / \mathrm{SI}_{2}\right) / b_{2}-b_{1}$, where $\mathrm{SI}_{1}$ is the signal intensity when the $b_{1}$ value is 0 , and $\mathrm{SI}_{2}$ is the signal intensity when the $b_{2}$ value is 800 . The other studies used $b$-values of 0 and 1000, a much higher $b_{2}$ factor than that in our study. According to the equation, the ADC value for $b=0-1000$ is higher than the value for $b=0-800$ because of the signal loss in DWI with the increasing $b$-value. ${ }^{20}$ Different MR imaging units may also have different ranges of ADC values as shown in the On-line Table.

In our study, the mean ADC values of benign lymph nodes were higher than the provided cutoff $\mathrm{ADC}$ value (Fig 1). However, some benign lymph node ADC values were lower than the cutoff value. Perrone et $\mathrm{al}^{7}$ indicated that the $\mathrm{ADC}$ values of benign lymph nodes in patients with tuberculosis are lower than the cutoff value, for example, for the malignant group. In future studies, a larger number of cases should be included to clarify the correlation between the ADC values of benign lymph nodes that are lower than the cutoff value and histopathologic findings.

DWI ADC calculation and ROC analysis (all lymph nodes, subcentimeter, and supracentimeter) presented higher sensitivity and specificity than conventional TSE MR imaging findings.

The size of the node and the size of intranodal tumor deposits varied widely in affected lymph nodes in the study of $\mathrm{Ng}$ et al. ${ }^{21}$ They showed that the mean percentage of tumor deposit within the affected nodes was $69.31 \% \pm 27.7 \%$, which is similar to the result $(74.3 \% \pm 30.2 \%)$ in our study. Previous studies ${ }^{22,23}$ indicated that there was a 
strong correlation between the intranodal tumor deposit and the size of the metastatic lymph node. ${ }^{24}$ This supports the use of nodal size as an index to evaluate preoperative nodal metastasis, but it remains a nonspecific feature of tumor-involved lymph nodes.

A potential problem of using the ADC cutoff value to distinguish malignant lymph nodes was that metastatic nodes with necrotic areas might have higher ADC values due to necrosis and might be incorrectly identified as benign. To avoid this bias, we calculated the ADC value from the region of interest drawn on the solid part of lymph nodes.

\section{CONCLUSIONS}

A cutoff ADC value of $0.851 \times 10^{-3} \mathrm{~mm}^{2} / \mathrm{s}$ best differentiated malignant from benign lymph nodes on $3 \mathrm{~T}$ MR imaging in the setting of head and neck cancer, with $91.3 \%$ sensitivity and $91.1 \%$ specificity to detect tumor-involved lymph nodes. Adding DWI to routine MR imaging neck protocols is suggested because it may provide useful information. The results in our study can be used as reference values for studies investigating head and neck lymph nodes by using $3 \mathrm{~T}$ MR imaging.

\section{REFERENCES}

1. Johnson JT. A surgeon looks at cervical lymph nodes. Radiology 1990;175:607-10

2. Yousem DM, Som PM, Hackney DB, et al. Central nodal necrosis and extracapsular neoplastic spread in cervical lymph nodes: MR imaging versus CT. Radiology 1992;182:753-59

3. van den Brekel MW, Castelijns JA, Snow GB. Detection of lymph node metastases in the neck: radiologic criteria. Radiology 1994;192:617-18

4. Sumi M, Sakihama N, Sumi T, et al. Discrimination of metastatic cervical lymph nodes with diffusion-weighted MR imaging in patients with head and neck cancer. AJNR Am J Neuroradiol 2003;24:1627-34

5. Vandecaveye V, De Keyzer F, Vander Poorten V, et al. Head and neck squamous cell carcinoma: value of diffusion-weighted MR imaging for nodal staging. Radiology 2009;251:134-46

6. Abdel Razek AA, Soliman NY, Elkhamary S, et al. Role of diffusionweighted MR imaging in cervical lymphadenopathy. Eur Radiol 2006;16:1468-77

7. Perrone A, Guerrisi P, Izzo L, et al. Diffusion-weighted MRI in cervical lymph nodes: differentiation between benign and malignant lesions. Eur J Radiol 2011;77:281-86

8. Herneth AM, Czerny C, Krestan C, et al. Role of diffusion weighted MRI in the characterization of lymph node metastases. In: Proceedings of the XVI International Congress of Head and Neck Radiology, Frankfurt/Main, Germany. September 4-6, 2003:C12

9. Srinivasan A, Dvorak R, Perni K, et al. Differentiation of benign and malignant pathology in the head and neck using 3T apparent diffusion coefficient values: early experience. AJNR Am J Neuroradiol 2008;29:40-44

10. Edge SE, Byrd DR, Compton CC, et al. AJCC Cancer Staging Manual. 7th ed. New York: Springer-Verlag; 2009

11. van den Brekel MW, Castelijns JA, Snow GB. The size of lymph nodes in the neck on sonograms as a radiologic criterion for metastasis: how reliable is it? AJNR Am J Neuroradiol 1998;19:695-700

12. King AD, Ahuja AT, Yeung DK, et al. Malignant cervical lymphadenopathy: diagnostic accuracy of diffusion-weighted MR imaging. Radiology 2007;245:806-13

13. Wang J, Takashima S, Takayama F, et al. Head and neck lesions: characterization with diffusion-weighted echo-planar MR imaging. Radiology 2001;220:621-30

14. Gray L, MacFall J. Overview of diffusion imaging. Magn Reson Imaging Clin N Am 1998;6:125-38

15. Hudgins PA, Anzai Y, Morris MR, et al. Ferumoxtran-10, a superparamagnetic iron oxide as a magnetic resonance enhancement agent for imaging lymph nodes: a phase $\mathbf{2}$ dose study. AJNR Am J Neuroradiol 2002;23:649-56

16. Markkola AT, Aronen HJ, Paavonen T, et al. Spin lock and magnetization transfer imaging of head and neck tumors. Radiology 1996;200:369-75

17. Maeda M, Kato H, Sakuma H, et al. Usefulness of the apparent diffusion coefficient in line scan diffusion-weighted imaging for distinguishing between squamous cell carcinomas and malignant lymphomas of the head and neck. AJNR Am J Neuroradiol 2005;26:1186-92

18. Sumi M, Takagi Y, Uetani M, et al. Diffusion-weighted echoplanar MR imaging of the salivary glands. AJR Am J Roentgenol 2002;178:959-65

19. Yoshino N, Yamada I, Ohbayashi N, et al. Salivary glands and lesions: evaluation of apparent diffusion coefficients with splitecho diffusion-weighted MR imaging-initial results. Radiology 2001;221:837-42

20. Thoeny HC, Ross BD. Predicting and monitoring cancer treatment response with diffusion-weighted MRI. J Magn Reson Imaging 2010;32:2-16

21. Ng SH, Yen TC, Liao CT, et al. 18F-FDG PET and CT/MRI in oral cavity squamous cell carcinoma: a prospective study of 124 patients with histologic correlation. J Nucl Med 2005;46:1136-43

22. Stuckensen T, Kovacs AF, Adams S, et al. Staging of the neck in patients with oral cavity squamous cell carcinomas: a prospective comparison of PET, ultrasound, CT and MRI. J Craniomaxillofac Surg 2000;28:319-24

23. Crippa F, Leutner M, Belli F, et al. Which kinds of lymph node metastases can FDG-PET detect? A clinical study in melanoma. J Nucl Med 2000;41:1491-94

24. Yamazaki Y, Saitoh M, Notani KI, et al. Assessment of cervical lymph node metastases using FDG-PET in patients with head and neck cancer. Ann Nucl Med 2008;22:177-84 